\title{
NIGHTTIME ABOVEGROUND MOVEMENTS BY PRAIRIE DOGS ON COLONIES INHABITED BY BLACK-FOOTED FERRETS
}

\author{
David A. Eads 1,5 , Jennifer G. Chipault ${ }^{2}$, Dean E. Biggins ${ }^{3}$, \\ Travis M. Livieri ${ }^{4}$, and Joshua J. Millspaugh ${ }^{1}$
}

\begin{abstract}
We describe observations of black-tailed prairie dogs (Cynomys ludovicianus) emerging aboveground at night, apparently in response to wild-born and captive-born black-footed ferrets (Mustela nigripes) in South Dakota and New Mexico, respectively. We also discuss other similar observations accumulated on black-tailed prairie dog colonies as well as observations of white-tailed prairie dogs (Cynomys leucurus) making nighttime movements, apparently in response to pre-reintroduction ferrets in Wyoming. Our observations suggest that, in addition to documented daytime defenses against ferrets, prairie dogs reduce vulnerability to predation by ferrets by using evasive movements at night.
\end{abstract}

Key words: prairie dog, Cynomys, black-footed ferret, Mustela nigripes, antipredator behavior, predator-prey relationships.

Prairie dogs (Cynomys spp.) are colonial, normally diurnal, ground-dwelling sciurids of the Great Plains of North America (King 1955, Hoogland 1995). Coloniality of prairie dogs and communication among them assist in alerting conspecifics to predators, thus aiding in antipredator defense (Hoogland 1995). Although these and other defenses might reduce risk of predation by diurnal predators (Hoogland 1981, 1995), prairie dogs are typically underground from dusk to dawn (Hoogland 1995). At night, such defenses might be relatively inefficient against semifossorial predators such as the black-footed ferret (Mustela nigripes).

Black-footed ferrets (hereafter, ferrets) are endangered mustelids (Miller et al. 1996, Biggins and Godbey 2003) that are highly dependent on prairie dogs as prey (Sheets et al. 1972, Campbell et al. 1987). Ferrets often hunt prairie dogs at night, capturing their prey in burrows (Vargas 1994, Miller et al. 1996, but see Clark et al. 1986) with kill bites, typically to the throat (Vargas and Anderson 1998). Prairie dogs might benefit from leaving burrow systems in which a ferret has initiated a hunt and seeking refuge in a different burrow.

There are few documented reports of nighttime aboveground activities of prairie dogs. Hoogland (1995) studied black-tailed prairie dogs (Cynomys ludovicianus) for 14 field seasons
(1,991 days in the field) in Wind Cave National Park, South Dakota, a site which at the time had been without ferrets for approximately 30 years. Hoogland (1995) suspected aboveground nocturnal movement by $<5$ females and $<5$ males, each of which had copulated late in the day. One other report of nighttime aboveground movement, unrelated to breeding, took place $>20$ minutes after all prairie dogs had descended into burrows for the night; at morning emergence, the location of an adult female and one of her young (each dye-marked) suggested that the animals switched burrows the previous night, presumably in response to excavation by an American badger (Taxidea taxus; Hoogland 1995, J.L. Hoogland unpublished data).

Monitoring of radio-tagged prairie dogs throughout the diel cycle (D.E. Biggins unpublished data on black-tailed prairie dogs, whitetailed prairie dogs [Cynomys leucurus], and Utah prairie dogs [Cynomys parvidens]) further suggests rarity of nighttime aboveground movements by prairie dogs. In that study, status of each of the approximately 150 radio-tagged prairie dogs was checked automatically at intervals of 5-15 minutes for up to 6 months. Radio signals from collared prairie dogs were seldom detected during hours of darkness (D.E. Biggins, unpublished data); radio signals were not audible from the monitoring station when prairie

${ }^{1}$ Department of Fisheries and Wildlife Sciences, 302 Anheuser-Busch Natural Resources Building, University of Missouri, Columbia, MO 65211.

${ }^{2}$ Department of Biology, Colorado State University, Fort Collins, CO 80523-1878.

${ }^{3}$ U.S. Geological Survey, Fort Collins Science Center, 2150 Centre Avenue, Building C, Fort Collins, CO 80526

${ }^{4}$ Prairie Wildlife Research, Box 308, Wellington, CO 80549.

5Present address: The Graduate Degree Program in Ecology, Colorado State University, Fort Collins, CO 80523-1878. E-mail: david.eads@ colostate.edu 
dogs were in burrows, except on rare occasions when prairie dogs were at shallow depths and burrows were close to the station.

The scarcity of published observations of nighttime emergence by prairie dogs suggests the phenomenon is rare. However, intensive observation of prairie dog colonies has often been concentrated at sites without ferrets and conducted primarily during daylight hours (e.g., Hoogland 1995). While conducting research on ferrets in South Dakota and New Mexico, we observed multiple instances of nighttime aboveground prairie dog movement, apparently in response to ferrets. Observers of specific behavioral episodes are identified by initials (if authors of this paper).

Observers drove a truck or all-terrain vehicle (ATV) 8-16 kmph and maneuvered a spotlight from side to side to detect the emerald green eyeshine of ferrets (Campbell et al. 1985, Biggins et al. 2006). Upon detecting a ferret and/or prairie dog (by body, not eyeshine), observers slanted the spotlight to expose the animal or animals to the minimum light required for observation. For information on light conditions during observations of prairie dogs, we used U.S. Naval Observatory estimates of times of sunset/sunrise (http://aa.usno.navy.mil/data /docs/RS_OneYear.php) at Interior, South Dakota, or Maxwell, New Mexico.

Between June and October 2007 in the Conata Basin, Buffalo Gap National Grasslands, South Dakota, DAE witnessed 3 instances of nighttime aboveground movement by blacktailed prairie dogs on a 452-ha colony inhabited by 12 wild-born, adult ferrets. DAE collected continuous focal observations (Altmann 1974) of each event with the aid of binoculars and later collected locations using a global-positioning receiver to calculate distances.

On 23 June 2007, at 01:52 (MDT; sunrise 05:07), DAE located a 5-year-old female ferret as it descended into a dome-crater (King 1955, Hoogland 1995) burrow opening. Approximately 30 seconds later, an adult prairie dog emerged from the opening and slowly walked aboveground until it descended into a nonmounded burrow opening $5 \mathrm{~m}$ away. The ferret emerged approximately 15 seconds later, scanned the immediate area, and continued its movements, extending its location to a distance $>20 \mathrm{~m}$ from the descended prairie dog.

On 3 August 2007, at 02:54 (sunrise 05:39), DAE located 2 adult prairie dogs emerging from a dome-crater burrow opening; the prairie dogs moved awkwardly (i.e., slowly and with apparent difficulty) aboveground and subsequently descended into a dome-crater burrow opening $12 \mathrm{~m}$ away, remaining aboveground for approximately 20 seconds. No ferrets were observed at this time. However, the event occurred in an area commonly utilized by a 2 year-old female ferret, and about one hour later, this ferret was found $21 \mathrm{~m}$ from the original location of these 2 prairie dogs.

On 15 August 2007, at 03:35 (sunrise 05:52), DAE located an adult prairie dog aboveground. The prairie dog awkwardly retreated to and descended into a dome-crater burrow opening $5 \mathrm{~m}$ from its initial location. Approximately 3 seconds after the prairie dog had descended, a 5-year-old female ferret (same ferret from 23 June observation) emerged from a rim-crater (Hoogland 1995) burrow opening $11 \mathrm{~m}$ from the descended prairie dog and assumed an "in-burrow alert posture" (sensu Clark et al. 1986:116). The ferret looked toward one of her kits located $21 \mathrm{~m}$ northeast of her location. Approximately 15 seconds after her initial emergence, the female ferret descended into the burrow opening from which she had appeared. Later in the survey $(\sim 04: 00)$ DAE approached this ferret to collect identification data from an automated passive-integrated-transponder reader; the ferret's mouth was caked with what appeared to be dry blood, suggesting she had attacked a prairie dog, perhaps inside the burrow system evacuated by the adult prairie dog earlier that night.

Between June and October 2008, during ferret-monitoring surveys on the Conata Basin colony, an observer witnessed 2 instances of nighttime aboveground movements by prairie dogs (D. Marsh personal communication). At 03:00 on 19 September (sunrise 06:32), a prairie dog emerged from a ferret-excavated burrow opening at which a 1-year-old male ferret had just been observed. The other event, involving one prairie dog, occurred between 02:00 and 03:00 on 25 September (sunrise 06:39) in an area frequented by a 3-year-old female ferret.

During spotlight surveys at Vermejo Park Ranch, New Mexico, from September 2007 through January 2008, JGC noted 2 instances of nighttime aboveground movement by blacktailed prairie dogs on a 416-ha colony where 26 captive-born ferrets were released on 4 September 2007. On 9 September 2007, at 
03:30 (sunrise 06:36), JGC located a prairie dog aboveground; the prairie dog walked slowly, with back legs spread, and passed by approximately 10 burrow openings without descending. From about $3 \mathrm{~m}$ away, JGC observed bloody wounds on the right side (injury approximately $5 \times 3 \mathrm{~cm}$ ) and both rear ankles of the prairie dog. Similar leg wounds were observed on another prairie dog known to have been attacked by a ferret (15 September, observation below), suggesting a ferret inflicted these wounds and induced aboveground movement. After about 2 minutes of observation, JGC vacated the area to minimize disturbance; the prairie dog had not descended into a burrow.

On 15 September 2007, at 19:50 (sunset 19:06), JGC heard prairie dog vocalizations (audible over the ATV engine) and, upon spotlighting the area, saw a prairie dog with its anterior half exposed aboveground and its forelegs braced on the rim of a mounded burrow opening. As JGC approached, the prairie dog moved away from the burrow opening; JGC inspected the opening and observed a male ferret kit in the burrow. The prairie dog was subsequently inspected from approximately $3 \mathrm{~m}$ away; JGC saw injuries on one rear leg and ankle. As in the 9 September sighting, this prairie dog seemed reluctant to descend into a burrow and walked with apparent difficulty past about 20 burrow openings but approached the ATV a few times before JGC vacated the area after about 5 minutes of observation.

No nighttime aboveground movements by prairie dogs were observed during ferret-monitoring sessions from August to October 2005, August to November 2006, and September to October 2008 at the Vermejo Park Ranch (J.G. Chipault personal observations; D.H. Long personal communication).

Nighttime aboveground movements of blacktailed prairie dogs near ferrets have been witnessed prior to these observations. In 1994, DEB observed a nighttime emergence of a prairie dog in the vicinity of a spotlighted, captive-born ferret that had descended into a burrow in Phillips County, Montana. At the Conata Basin on 4 October 2002 (sunrise 06:49), TML observed a wild-born, 2-year-old male ferret entering a prairie dog burrow at about 05:00. Within minutes, 4 prairie dogs emerged from the burrow and awkwardly moved toward and descended into nearby burrow openings. At the Conata Basin on 8 October 2003 (sunrise 06:53),
TML observed a ferret in a dome-crater burrow opening at 00:30 and set a live trap in the opening. When TML checked the trap at 01:14, it was occupied by a prairie dog. At 01:45 the following night, TML observed a ferret in the same burrow opening and subsequently trapped and identified it as a wild-born female kit. At 22:00 on 20 June 2006 (sunset 20:33) at the Conata Basin, 2 observers located a wild-born ferret as it descended into a burrow opening; approximately 20 seconds later, 2 prairie dogs bolted from the burrow opening (D.S. Jachowski personal communication).

Emergences of prairie dogs near ferrets were also seen during spotlight searches in whitetailed prairie dog colonies near Meeteetse, Wyoming, during 1982-1985. DEB witnessed a white-tailed prairie dog emerging at night, apparently in response to a nearby ferret that had descended into a burrow. B.J. Miller (personal communication) observed a white-tailed prairie dog aboveground at dawn (prior to the emergence of other prairie dogs on the colony) in the vicinity of a female ferret he had been watching. These observations, collected on white-tailed prairie dogs in the presence of a native population of ferrets (prior to captive breeding and reintroduction) suggest (1) that black-tailed and white-tailed prairie dogs might react similarly to the presence of ferrets at night and (2) that nighttime escape is not a novel reaction to novel predatory behaviors that developed during captive propagation of black-footed ferrets.

The predatory experience of ferrets (wildvs. captive-born), and the antipredatory experience of prairie dogs might have influenced the interactions and outcomes of the encounters. Predatory efficiency of captive-born ferrets increases with exposure to live prairie dogs and following observation of kills by dams (Vargas and Anderson 1998). Being less experienced with wild prairie dogs (relative to wild-born ferrets), captive-born ferrets from Vermejo Park Ranch (2007) and Phillips County (1994) might have been learning to hunt. Perhaps at Vermejo Park Ranch, killing behaviors were not efficiently established 5-11 nights postrelease. In contrast, the Meeteetse (1982-1985) and Conata Basin (2006 and 2007) ferrets were wild-born predators. Possible explanations for why prairie dogs escaped these wild-born ferrets include (1) the ferrets had targeted prairie dogs other than those observed; (2) the prairie dogs were 
experienced prey and thus more capable of escape; (3) prairie dogs have other, as yet unknown defenses against within-burrow attacks by ferrets; and/or (4) the ferrets were not hunting at the time of observation. Chance also influences predation events (Caro 2005).

Observations made by others during daylight suggest that prairie dogs are capable of numerous defenses against ferrets, including alarm calling (Henderson et al. 1969), increased vigilance (Shier and Owings 2006), defensive burying (Hillman 1968, Henderson et al. 1969, Progulske 1969, Hillman and Linder 1973, Martin et al. 1984, Jachowski 2007), avoidance (Hillman 1968, Henderson et al. 1969, Hillman and Linder 1973), and counterattack (e.g., biting [Progulske 1969] or hazing [Jachowski 2007]). Here we documented observations of nighttime aboveground movement, a nighttime defense by normally diurnal prairie dogs. Relatively little is known about prairie dog defenses within burrow systems (but see Miller et al. 1996, Vargas 1994). Within-burrow defenses of prairie dogs might often precede nighttime aboveground movements. Innovative research might document the details of some within-burrow prairie dog defenses against ferrets and perhaps reveal previously unobserved defense behaviors.

We thank the South Dakota Department of Game, Fish and Parks; the University of Missouri; the National Fish and Wildlife Foundation; the U.S. Fish and Wildlife Service (Conata Basin); and the Turner Endangered Species Fund (Vermejo Park Ranch) for funding the research that made these observations possible. DAE was also supported by S. and D. Webb. Observations of nighttime black-tailed prairie dog movements were greatly enhanced by field help from D. Marsh and D.L. Eads (Conata Basin) and from K.A. Montgomery (Vermejo Park Ranch). We appreciate the help of B.J. Miller, D.S. Jachowski, and J.L. Hoogland, who provided details of their observations. We also appreciate the constructive reviews and comments of J.L. Hoogland, J.C. Truett, D.S. Jachowski, and an anonymous reviewer, and discussions with D.H. Long, S.L. Eads, M.F. Chipault, T.R. Eads, and D.L. Eads.

\section{Literature Cited}

Altmann, J. 1974. Observational study of behavior: sampling methods. Behaviour 49:227-267.
Biggins, D.E., And J.L. Godbey. 2003. Challenges to reestablishment of free-ranging populations of black-footed ferrets. Comptes Rendus Biologies 326:S104-S111.

Biggins, D.E., J.L. Godbey, M.R. Matchett, L.R. Hanebury, T.M. Livieri, and P.E. Marinari. 2006. Monitoring black-footed ferrets during reestablishment of free-ranging populations: discussion of alternative methods and recommended minimum standards. Pages 155-174 in J.E. Roelle, B.J. Miller, J.L. Godbey, and D.E. Biggins, editors, Recovery of the black-footed ferret: progress and continuing challenges-Proceedings of the Symposium on the Status of the Black-footed Ferret and its Habitat. U.S. Geological Survey, Fort Collins, CO.

Campbell, T.M., III, D. Biggins, S. Forrest, and T.W. Clark. 1985. Spotlighting as a method to locate and study black-footed ferrets. Pages 24.1-24.7 in S.H. Anderson and D.B. Inkley, editors, Black-footed ferret workshop proceedings. Wyoming Game and Fish Department, Cheyenne, WY.

Campbell, T.M., III, T.W. Clark, L. Richardson, S.C. ForRest, AND B.R. Houston. 1987. Food habits of Wyoming black-footed ferrets. American Midland Naturalist 117:208-210.

Caro, T. 2005. Antipredator defenses in birds and mammals. University of Chicago Press, Chicago, IL.

Clark, T.W., L. Richardson, S.C. Forrest, D.E. Casey, and T.M. Campbell. 1986. Descriptive ethology and activity patterns of black-footed ferrets. Great Basin Naturalist Memoirs 8:115-134.

Henderson, F.R., P.F. Springer, And R. Adrian. 1969. The black-footed ferret in South Dakota. South Dakota Department of Game, Fish, and Parks Technical Bulletin 4.

Hillman, C.N. 1968. Field observations of black-footed ferrets in South Dakota. Transactions of the North American Wildlife and Natural Resources Conference 33:433-443.

Hillman, C.N., AND R.L. Linder. 1973. The black-footed ferret. Pages 10-20 in R.L. Linder and C.N. Hillman, editors, Proceedings of the Black-footed Ferret and Prairie Dog Workshop. South Dakota State University, Brookings, SD.

Hoogland, J.L. 1981. The evolution of coloniality in white-tailed and black-tailed prairie dogs (Sciuridae: Cynomys leucurus and C. ludovicianus). Ecology 62:252-272.

. 1995. The black-tailed prairie dog: social life of a burrowing mammal. University of Chicago Press, Chicago, IL.

JACHOWSKI, D.S. 2007. Notes on black-footed ferret detectability and behavior. Prairie Naturalist 39:97-102.

KING, J.A. 1955. Social behavior, social organization, and population dynamics in a black-tailed prairiedog town in the Black Hills of South Dakota. Contributions from the Laboratory of Vertebrate Biology, University of Michigan, No. 67. Ann Arbor, MI.

Martin, S.J., M.H. Schroeder, and H. Tietjen. 1984. Burrow plugging by prairie dogs in response to Siberian polecats. Great Basin Naturalist 44:447-449.

Miller, B., R.P. Reading, and S.C. Forrest. 1996. Prairie night: black-footed ferrets and the recovery of endangered species. Smithsonian Institution Press, Washington, DC. 
Progulske, D.R. 1969. Observations of a penned, wildcaptured black-footed ferret. Journal of Mammalogy 50:619-621.

Sheets, R.G., R.L. Linder, And R.B. Dahlgren. 1972. Food habits of two litters of black-footed ferrets in South Dakota. American Midland Naturalist 87: 249-251.

SHIER, D.M. AND D.H. OwINGs. 2006. Effects of predator training on behavior and post-release survival of captive prairie dogs (Cynomys ludovicianus). Biological Conservation 132:126-135.
VARGAS, A. 1994. Ontogeny of the endangered black-footed ferret (Mustela nigripes) and effects of captive upbringing on predatory behavior and post-release survival. Doctoral dissertation, University of Wyoming, Laramie, WY.

Vargas, A., AND S.H. Anderson. 1998. Ontogeny of black-footed ferret predatory behavior towards prairie dogs. Canadian Journal of Zoology 76:1696-1704.

Received 12 March 2009 Accepted 7 January 2010 